\title{
Segregação Espacial e Segregação Escolar: Notas para uma Sociologia da Distribuição Espacial e Social dos Estabelecimentos de Ensino
}

\author{
JuAREZ Lopes de CARVAlHo Filho ${ }^{1}$
}

\begin{abstract}
Resumo
Este artigo objetiva oferecer um quadro analítico para uma sociologia da distribuição espacial e social dos estabelecimentos de ensino. A expansão dos ideais republicanos, resultante da "democratização escolar", engendrou um prolongamento dos estudos, da diversificação dos estabelecimentos de ensino, das modalidades de fileiras e opções propostas aos filhos tanto da elite quanto da classe popular. Doravante, não basta os pais colocarem seus filhos na escola. É preciso colocá-los numa "boa escola" que possa lhes assegurar um futuro promissor. Isso exige um conhecimento do sistema de ensino, da situação social do estabelecimento, disposição de tempo, capital econômico e capital cultural. Ou seja, um conjunto de disposições e condições objetivas, que são repartidas de maneiras desiguais entre as famílias. Após recuperar o sentido da segregação para a sociologia geral e da educação, este texto faz referência a um conjunto de trabalhos que articulam segregação social e segregação escolar, esboçando um quadro analítico para uma sociologia da distribuição espacial e social dos estabelecimentos de ensino, problemática inovadora para a sociologia da educação nos últimos vinte anos.
\end{abstract}

Palavras-chave: Segregação social. Segregação escolar. Escolha dos estabelecimentos. Reprodução social.

1 Professor do Departamento de Sociologia e Antropologia e membro do corpo docente do Programa de Pós-Graduação em Ciências Sociais da Universidade Federal do Maranhão (UFM), Brasil.juarez. lopes@gmail.com 


\title{
Spatial Segregation and School Segregation: Notes for a Sociology of Social and Spacial Distribution of Educational INSTITUTIONS
}

\begin{abstract}
This article aims to provide an analytical framework for a sociology of social and spatial distribution of schools. The expansion of republican ideals, resulting from the "school democratization", engendered a prolongation of studies, diversification of schools, terms of rows and proposed options to the children of both the elite and the working class. Henceforth, not just parents put their children in school. You need to put them in a "good school" that can assure a promising future. This requires knowledge of the education system, the social situation of the establishment, provision of time, economic and cultural capital. That is, a set of provisions and objective conditions, which are distributed in unequal ways between families. After recovering the meaning of segregation for general sociology and education, this text refers to a set of works that articulate social segregation and school segregation, outlining an analytical framework for a sociology of social and spatial distribution of schools, an innovative problem for the sociology of education in the last twenty years.
\end{abstract}

Keywords: Social segregation. School segregation. Choice of establishments. Social reproduction.

\section{INTRODUÇÃo}

Este artigo propõe alguns postulados para uma sociologia da distribuição espacial e social dos estabelecimentos de ensino ${ }^{2}$. Acentuase o problema das desigualdades sociais de escolarização, que foi objeto da sociologia da educação, notadamente na França, desde os anos de 1960, mas articulando aqui dois aspectos: a segregação espacial e a segregação escolar, uma perspectiva recente, mas bastante promissora no interior da sociologia da educação nos últimos anos.

2 Uma primeira versão deste trabalho foi apresentada no IV Encontro Internacional de Ciências Sociais

- Espaços Públicos, Identidades e Diferenças, UFPEL, Pelotas-RS, de 19 a 21 de novembro de 2014, em formato de comunicação oral. Esta segunda versão foi revisada e ampliada em todas as suas seções. É o resultado da primeira etapa da pesquisa Segregação espacial e segregação escolar: sociologia da distribuição espacial e social dos estabelecimentos de ensino em São Luis-MA, financiada pela FAPEMA. 
Entre outros objetivos, visa-se contribuir com o conjunto de pesquisas sobre as escolhas dos estabelecimentos de ensino, relacionando o processo de socialização e escolarização das famílias. A sociologia da escolha dos estabelecimentos de ensino foi inicialmente desenvolvida na Europa, nos Estados Unidos, e, nos últimos anos, no Brasil. Neste último ela encontrou espaço de produção nos vastos trabalhos do GT Sociologia da Educação da ANPED (Associação Nacional de Pós-Graduação e Pesquisa em Educação) e divulgados através de coletivos tais como Família e Escola: trajetórias de escolarização em camadas médias e populares e Família e Escola: novas perspectivas de análise, coordenados por Geraldo Romanelli, Maria Alice Nogueira e Nadir Zago (2011, 2013). No conjunto, estes trabalhos se alicerçam na sociologia da educação e da cultura produzidas na França, em especial nos trabalhos de P. Bourdieu, entre outros, e, assim, propõem novas abordagens teóricas e metodológicas contribuindo para solidificar os fundamentos da sociologia da educação brasileira, alargando sua produção sobre as relações entre família e escola.

Destacam-se aqui os trabalhos realizados sob a égide de Maria Alice Nogueira e Ana Maria F. Almeida (2003). Elas conjugam, em suas análises, a escolha do estabelecimento de ensino com o processo de socialização das famílias e a escolarização das elites. Ou seja, buscam compreender e explicar a relação complexa entre família e instituição escolar, "focalizando as experiências de escolarização que certas famílias mais privilegiadas podem proporcionar a seus filhos ao prepará-los para as posições dirigentes" (ALMEIDA, 2009, p. 21).

Em artigo intitulado $A$ escolha do estabelecimento de ensino pelas famílias: a ação discreta da riqueza cultural, Nogueira postula que "as famílias ou diferentes meios sociais são desigualmente equipados no que se refere às condições necessárias à "boa" escolha do estabelecimento escolar para seus filhos" (NOGUEIRA, 1998, p. 43). A referida autora investiga em que medida as estratégias de escolher 
o estabelecimento de ensino variam de natureza quando se passa de um meio social a outro ou de uma família a outra no interior de um mesmo universo social. Ela lembra igualmente, que o que está em jogo e no centro dos discursos no campo das relações entre família/escola é o grau de autonomia que pode atribuir a variável família em relação à variável social.

A sociologia da distribuição espacial e social dos estabelecimentos de ensino, esboçada aqui, destaca um conjunto de trabalhos produzidos na França sobre a escola segregativa, um novo modo de reprodução social das desigualdades de acesso à escolarização. Como demonstrou Pierre Merle, a "segregação escolar" renova progressivamente as modalidades de escolarização dos alunos. Em análises comparativas no âmbito internacional, ele atesta que o "nível de segregação escolar varia consideravelmente segundo as organizações educativas nacionais e exerce efeitos sensíveis no nível de competências de seus alunos e no nível de igualdade de oportunidades" (MERLE, 2012, p. 6).

Após recuperar em que contexto a expressão "democratização escolar" se torna objeto de discussão, trata-se neste texto, ainda que brevemente, do significado da "segregação" no âmbito da sociologia em geral e no contexto da sociologia da educação em particular. Como se sabe, a segregação, sempre foi um tema polissêmico e polêmico nas ciências sociais. No entanto, como enfatizam Ben Ayed e Poupeau (2009), a questão da segregação social vinculada à segregação escolar impõe-se como uma questão central, uma vez que a noção de segregação remete em primeiro lugar a uma descrição empírica das disjunções espaciais entre áreas de residência de grupos de população vivendo numa mesma aglomeração e depois a formas de discriminação e exclusão social que vão além da distância espacial ${ }^{3}$.

3 Tradução livre do autor, exceto quando indicado. 
Na última parte do texto, faz-se alusão a algumas pesquisas que inovaram os estudos no âmbito desta disciplina, focalizando a influência da distribuição do espaço social no processo de escolarização. Nesse sentido, enseja-se contribuir, a partir de uma revisão da literatura, com a circulação de uma sociologia da distribuição espacial e social dos estabelecimentos de ensino, já existente em outros países como a França, compreendendo que as estratégias sociais e as experiências escolares que as famílias impõem aos seus filhos produzem "a maneira como frações dos grupos dirigentes se definem e se auto-classificam construindo, ao longo do processo, fraturas e articulações entre eles próprios e os grupos menos favorecidos" (ALMEIDA, 2009, p. 21-22).

\section{Da "Eficácia" à “Democratização" do Ensino}

A passagem do discurso da "eficácia" do sistema de ensino ao da "democratização" (BEN AYED; POUPEAU, 2009) se dá no processo de expansão da "escola republicana". É claro que o tema da democratização do ensino não é novo. Ele foi bastante desenvolvido enquanto reivindicação sociopolítica visando transformar o sistema de ensino e escolar, em nome das "desigualdades de chance". No entanto a expressão "democratização do ensino" foi bastante criticada em várias pesquisas no campo da sociologia da educação nos anos 19601970. Nesse último caso, a ideia era mostrar as ambiguidades da noção e desvelar as discordâncias entre os discursos comuns, os discursos governamentais (otimistas republicanos) e sindicais. P. Bourdieu e J.-C. Passeron com Os Herdeiros: os estudantes e a cultura, publicado em 1964 (traduzido no Brasil em 2014, 50 anos depois), esboçam as bases de um sistema de ensino "realmente democrático" que tentam de maneira racional neutralizar os fatores das desigualdades culturais frente à e no interior da "Escola". No livro A reprodução: elementos para uma teoria do sistema de ensino, (BOURDIEU; PASSERON, 1999) eles sublinham a 
translação rumo ao topo das desigualdades sociais e sua manutenção, apesar da expansão de acesso e do desenvolvimento das escolaridades. A partir daí, vários estudos têm abordado esse problema colocando a questão da segregação escolar e social num processo crescente de “democratização do ensino" (BEAUD, 2002; MERLE, 2011).

Isso dito, não se pode desconsiderar que a expansão dos ideais republicanos, expressa no processo de "democratização escolar" (caso na França, mas encontrado, também, em outros países), resultou num prolongamento dos estudos, da diversificação dos estabelecimentos de ensino, das modalidades de fileiras e opções propostas aos filhos, não somente da elite, mas também da classe popular. Doravante, não basta somente os pais colocarem seus filhos nas escolas. É preciso colocá-los numa "boa escola" que possa lhes assegurar um futuro promissor ou garantir a conservação dos recursos acumulados já garantidos. Isso exige um conhecimento do sistema de ensino em várias dimensões: domínio da situação social do estabelecimento, da orientação filosófica e pedagógica da educação proposta pela escola, disposição de tempo e a mobilização de um capital econômico e cultural. Ou seja, um conjunto de disposições interiorizadas e condições objetivas, que são repartidas de maneiras desiguais entre os grupos sociais. Nesse sentido a problemática da segregação escolar reúne objetos diversos, tais como: as estratégias familiares de "localização escolar", as políticas de distribuição dos alunos dentro e entre os estabelecimentos escolares; ou ainda, o papel administrativo do Estado na produção e na reprodução dessas segregações (BEN AYED; POUPEAU, 2009, p. 6). Como se percebe, a questão das segregações estabelece igualmente uma relação estreita com a problemática das desigualdades sociais. A "democratização do ensino" nos países mais industrializados, como a França, não fez desaparecer nem as desigualdades sociais nem as desigualdades escolares. Como observa Camille Peugny (2014) em trabalho sobre desigualdades e reprodução social, apesar de meio 
século de massificação escolar, a reprodução social das desigualdades perdura em nível bastante elevado.

Frente a esse quadro, a distribuição espacial e social dos estabelecimentos escolares redobra as desigualdades de chance. A segregação escolar, uma realidade social, geralmente ignorada pelos agentes oficiais da educação, nos inspira mais a falar em termos de diversificação da trajetória escolar dos alunos, do que de condições objetivas sociais que condicionam diretamente o fracasso e os êxitos sociais.

Diante das "desigualdades sociais, a referência à noção de reprodução é doravante frequentemente remobilizada nas análises da escola" (BEN AYED; POUPEAU, 2009, p. 5). Assiste-se assim ao longo das últimas décadas depois dos anos de 1980, quando há um declínio de estudos macrossociológicos, a uma variedade de objetos que concorrem para uma renovação e institucionalização da sociologia da educação em geral, e da sociologia da escolha e distribuição dos estabelecimentos escolares, que exercem um papel importante no processo de escolarização, da construção das visões de mundo, através das quais os grupos sociais elaboram estratégias e modos de se representar e de representar os outros no mundo social.

\section{O Sentido da Segregação na Sociologia: Distância Espacial e Distância Social}

Sabe-se que a noção de "segregação" é um termo polissémico em diferentes esferas, indo do senso comum ao sentido erudito, do registro técnico ao político e científico. Sociologicamente a segregação é uma forma institucionalizada de distância social que se traduz por uma separação espacial. No entanto, segundo Payet (1998, p. 22), ela não equivale a um conceito formal, mas operatório, nos campos particulares de análises, intrinsecamente ligada ao debate ideológico 
Para Grafmeyer (1995, p. 35), quando se fala de segregação urbana, é geralmente para qualificar as formas as mais nítidas de divisão social do espaço. No entanto, é uma maneira de falar e de interpretar os princípios explicativos e a significação social dos fatos que se observa. Utilizado em primeiro lugar de maneira mais sistemática pela Escola de Chicago para estudar concretamente os fenômenos de segregação espacial e compreender as leis de desenvolvimento do cidadão nos célebres trabalhos de Louis Wirth sobre os guetos ${ }^{4}$, a noção de segregação se torna, nos anos 1930 e 1940, no seu aspecto racial, uma categoria central nas ciências sociais, sobretudo quando, nos Estados Unidos, se torna evidente que os Negros, contrariamente às outras minoridades, ditas étnicas são vítimas de um processo de distanciamento, que torna mais difícil a inserção social e a coabitaçãos.

Essa discussão levada em conta, a noção de segregação social é utilizada aqui no sentido dado por Grafmeyer (1995, p. 39-40) que a compreende como um fato social ao mesmo tempo de mise à

4 Outros trabalhos se celebrizaram na abordagem do gueto, como Sociedade de esquina: a estrutura social de uma área urbana pobre e degradada, de William Foote Whyte (2005).

5 Embora não seja possível abordar aqui de maneira aprofundada sobre a segregação étnicoracial, é importante explicar que apesar de alguns autores afirmarem que o processo de "guetorização" não se restrinja apenas ao contexto americano, sendo também verificável na Europa, o processo de organização social interna e posições socioespaciais da ordem simbólica das metrópoles nos dois continentes se revelam distintos tanto socialmente como historicamente, apesar de aproximações no que concerne ao processo de desindustrialização e avanço da pobreza, brutal e caótica. No contexto Francês, os discursos construídos que assimilam as grandes periferias parisienses industriais (banlieues) em processo de pauperização aos guetos americanos é um "trabalho de dramatização operada por jornalistas ao longo dos últimos 20 anos impondo uma representação unívoca das "cités HLM" (Habitation à loyer moderé, conjuntos habitacionais de alugueis populares), em termos de delinquência e inseguridade (as famosas "violências urbanas") (MASCLET, 2005, p. 11). Os trabalhos de L. Wacquant, « Pour en finir avec le mythe des cités-ghettos. Les différences entre la France et les États-Unis » (1992) e Parias Urbains : ghetto-banlieues-État (2006), também são importantes para romper com os discursos midiáticos e políticos, que misturam categorias (gueto, periferia, bairros, rancho, favelas) do seu repertório para pensar a marginalidade urbana. Para este autor "banlieue ouvrière" (periferia operária) e gueto negro americano são objetos de construções políticas e de gestões burocráticas diametralmente opostas. Ou seja, existe uma distância que separa essas duas constelações socioespaciais seja do ponto de vista da ordem quantitativa quanto e, fundamentalmente, da ordem sociohistórica e institucional (WACQUANT, 2006, p. 146). 
distance e uma separação física. Ela está permanentemente na tensão entre essas duas ordens de realidade. Para este autor a problemática da segregação coloca em jogo uma questão geral de relações que os fenômenos de proximidade e de distâncias sociais mantêm com uma eventual tradução no espaço urbano. No entanto, é bom lembrar que a separação física de grupos socialmente distintos não constitui uma lei universal, sendo nesse caso o resultado de um processo específico que convém dar conta e precisar social e historicamente.

Como se vê, a segregação concebida nessa perspectiva é tomada como um processo, que segundo Y. Fijalkow (2002, p. 55-56), é de uma grande complexidade, sendo resultado de vários fatores. Convém lembrar, por exemplo: os preços do mercado imobiliário determinam em grande parte a implantação de tipos de residências. Os preços são, geralmente, o efeito de uma concorrência entre diversas formas de uso do solo, notadamente entre a forma do setor terciário e a residencial. Foi dentro desta lógica que várias capitais ocidentais (Paris, Londres, Nova York) construíram seu parque imobiliário e conhecem, atualmente, preços bastante elevados no mercado imobiliário (fenômeno que se verifica também no Brasil). Além disso, o processo de segregação é impactado pelas políticas de urbanização, como a destruição de bairros populares, e o aumento do aluguel pressiona as famílias de classe popular a se deslocarem para a periferia.

O problema do transporte e as distâncias do lugar de trabalho também pesam nas escolhas do lugar de residências. No entanto, os aspectos simbólicos não devem ser negligenciados. Como afirma Fijalkow (2002, p. 56):

[...] o espaço é socialmente diferenciado do ponto de vista da riqueza e do poder; ele se organiza entre o centro e as periferias, o alto e o baixo, "la rive droite et la rive gauche" . Esse esquema mental é de tal forma incorporado nos modos de vida dos habitantes que o endereço passa a

6 As margens direita e esquerda do rio Sena, em Paris, França. 
fazer parte do capital simbólico. Ele permite ser associado a uma rede social e profissional.

Como já mostrara C. Charle em estudo sobre o campo literário francês do final do século XIX, nessa época, o espaço parisiense era bastante marcado por características sociais segundo o bairro.

Que se trate da alta costura, da arte ou da literatura, os agentes e as instituições se encontram distribuídos no espaço parisiense segundo uma geografia socialmente diferenciada e se constata um homologia nitidamente caracterizadas entre as diferenciações internas do campo considerado e a distribuição das instituições no espaço (CHARLE, 1977, p. 85).

Dito de outra forma, a trajetória social e geográfica dos romancistas é geralmente ligada ao seu pertencimento a uma das escolas literárias dominantes daquela época (simbolismo, naturalismo, psicologismo).

Para o propósito deste artigo, no que concerne à problemática da segregação escolar, é importante lembrar ainda a orientação de J.-P. Payet (1998, p. 22), segundo a qual a segregação escolar demanda ser descrita e analisada com uma diferenciação das populações escolares de um estabelecimento a outro no interior de um "mercado escolar local" e no seio de um estabelecimento entre as diferentes classes sociais de um mesmo nível de escolaridade. Necessita ainda, uma leitura do trabalho dos agentes sociais em termos de diferenciação espacial das carreiras profissionais e divisão do trabalho no interior do estabelecimento.

\section{Segregação Urbana e Segregação Escolar}

$\mathrm{Na}$ França, a observação em diferentes escalas sobre o processo de segregação permite medir o peso dos diferentes fatores: sociais, econômicos, políticos, culturais, escolares, étnicos. Na medida 
em que o espaço urbano é segregado, os estabelecimentos escolares o são também, uma vez que a setorização introduz um laço mecânico entre segregação urbana e segregação escolar (DURU-BELLAT, 2004). Assim, a setorização espacial das políticas escolares pode influenciar sobre as estratégias de localização do domicílio com os filhos: a vontade de se aproximar de zonas de recrutamento dos liceus preparando para as "grandes escolas"7 e evitar os colégios estigmatizados e em dificuldades (VAN ZANTEN, 2001 apud FIJALKOW, 2002, p. 56).

Antes de abordar aqui a relação estreita, mas não a única, entre segregação urbana e segregação escolar, é importante levar em conta o que está por trás e em jogo, nesse problema, a saber, o que significa a "carte scolaire", na França. Segundo J.-P. Obin e A. van Zanten, comumente hoje se compreende por "carte scolaire"

[...] um conjunto de dispositivos que se destinam a definir a oferta da escola pública e tratar a demanda educacional de famílias. Originalmente, o termo foi criado para descrever o processo de elaboração da oferta escolar pela administração de Educação nacional: implementação e construção de estabelecimentos, abertura e fechamento de escolas, definindo a sua capacidade de alojamento, localização de cursos especializados, opções e modalidades do Baccalauréat ${ }^{9}$ e distribuição corolário dos meios necessários em termos de postos e horas de ensino. O tratamento da demanda educacional e alocação dos estudantes, tendo sido durante muito tempo de responsabilidade dos diretores dos estabelecimentos foi confiado à administração da Educação nacional em $1963^{10}$, pela atribuição de um sector geográfico de

7 As "Grandes escolas" na França, correspondem às Instituições de ensino superior, independentes do sistema universitário, que recrutam por meio de concurso e se destinam a formar as elites intelectuais e dirigentes.

8 Mapa escolar, lei de setorização de matrículas.

9 Exame nacional que sanciona o curso secundário francês e serve de ingresso à universidade.

10 A "Carte scolaire" foi criada em 1963 pelo ministro Christian Fouchet, visando melhor gerir os colégios (de $5^{\underline{a}}$ a $8^{\underline{a}}$ série) e os liceus (ensino médio). No momento de matricular seus filhos na escola, os pais não têm o direito de escolher o estabelecimento no qual não querem que seus filhos estudem. A "carte scolaire" supõe dois aspectos: primeiro, a distribuição geográfica dos professores; e, em segundo, a distribuição dos alunos de acordo com o lugar de residência. 
recrutamento bem delimitado a qualquer estabelecimento de "setorização» (OBIN; VAN ZANTEN, 2010, p. 3).

Como se vê, a "carte scolaire" é um dispositivo administrativo de políticas nacionais de regulação da oferta escolar e da demanda da educação. Esse dispositivo se encontra no cruzamento de vários interesses sociais e políticos. De uma parte, o aménagement (transformação) territorial por meio de questões como a proximidade, a diversidade e a qualidade da oferta em meio rural; de outra, as políticas escolares urbanas, em razão do papel exercido por esse dispositivo na manutenção dos estabelecimentos públicos em bairros populares no que diz respeito à equidade de oferta escolar e à diversidade social (OBIN; VAN ZANTEN, 2010, p. 5-6).

De todo modo, a política de setorização foi objeto de vários debates, e está longe de ser um consenso entre intelectuais, agentes sociais da educação e políticos. A partir de 1980 vários ministros tentaram implantar políticas de setorização em vista de abrandar ou flexibilizar a "carte scolaire", ou mesmo anunciaram sua supressão em 2007. De um lado existem aqueles que reivindicando a supressão da "carte scolaire" afirmam que impediria as famílias de escolher livremente o estabelecimento de seu filho; em oposição a isso estão os que afirmam que a regulação pelo mercado e a concorrência dos estabelecimentos de ensino permitiria acentuar as desigualdades sociais de escolarização. Para F. Dubet a oferta escolar está longe de ser igual e homogênea. Segundo ele:

O mapa escolar registra as desigualdades sociais e suas imposições são mais rígidas para os pobres encerrados nos estabelecimentos dos "guetos", onde a concentração de alunos relativamente fracos enfraquece ainda mais o nível geral, reduzindo suas chances de êxito, inclusive para os bons alunos. Ao contrário, as concentrações de bons alunos em estabelecimentos favorecidos, reforçam a qualidade da educação e o nível médio dos alunos. Acrescentamos que uma parte das classes médias, 
especialmente pais e professores, escapa às imposições do mapa escolar quando elas não lhes são favoráveis, graças ao recurso ao ensino privado e ao jogo das derrogações (DUBET, 2008, p. 34)11.

É importante ressalvar que apenas a partir de 1980, na França, a questão das desigualdades de escolarização no espaço urbano foi colocada. As pesquisas francesas tomaram por objeto as estratégias de evitamento ou derrogação da lei de setorização da matrícula (à qual grande número de famílias recorrera ao longo dos anos 1980) para ter acesso não só a excelentes estabelecimentos fora do setor, mas também a uma importante oferta de atividades culturais e esportivas da norma administrativa (POUPEAU; FRANÇOIS, 2008, p. 168). Esses trabalhos colocaram em evidência a necessidade para as famílias de beneficiarse de certo número de recursos (acesso à informação, mobilidade, por exemplo) para escolher o estabelecimento mais adaptado a seus projetos. Como sublinham Poupeau e François (2008, p. 168), a partir de 1980, geógrafos realizaram pesquisas descritivas sobre as formas de segregação social e espacial, paralelas às abordagens políticas, denunciando os processos de marginalização e descriminação, mas o espaço escolar continuava relativamente pouco abordado. Eles afirmam que os problemas de segregação no espaço urbano eram principalmente estudados sob o ângulo da distribuição espacial de três tipos de comportamento: "habitar, trabalhar, consumir" (OBERTI, 1995 apud POUPEAU; FRANÇOIS, 2008, p. 168). Somente então, a partir de 1980, as desigualdades de escolarização no meio urbano passaram a ser abordadas pela geografia e pela sociologia da educação (POUPEAU; FRANÇOIS, 2008; VAN ZANTEN, 1991 apud FRANÇOIS; POUPEAU, 2005): essas duas disciplinas, a partir de expectativas específicas, concentram-se progressivamente sobre os estudos dos fluxos escolares entre estabelecimentos, num contexto

11 Tradução de Ione Ribeiro Valle. 
onde as políticas nacionais de democratização escolar fizeram da escola um tema central, com forte interesse local. Assim, uma análise na perspectiva geográfica das diferenciações espaciais, de uma parte, e uma sociologia do evitamento escolar, de outra parte, pode convergir para pesquisas comuns (POUPEAU; FRANÇOIS, 2008, p. 169).

Para van Zanten (1991 apud FRANÇOIS; POUPEAU, 2005, p. 368), duas condições aparecem como necessárias quando se trata de segregação escolar: a primeira é que é preciso colocar em evidência que a concentração escolar de certas populações resulta não somente de fatores externos, mas, de fatores, pelo menos em parte, da ação específica da instituição escolar e de seus agentes. A segunda é que, para falar de segregação escolar é preciso estar em condições de mostrar que a segregação espacial na escola conduz à produção de formas específicas de desigualdades ou de exclusão escolares e sociais.

Apesar das pesquisas sobre a segregação urbana e a segregação escolar apresentarem tomadas de posição às vezes divergentes, algumas orientações aparecem em comum, e concorreram para institucionalizar essa problemática sociológica que leva em conta a segregação escolar no meio urbano. Por questão de ilustração, que se consagraram nesse domínio, refere-se aqui aos trabalhos de van Zanten, L'école et l'espace local (1990), L'école de la périphérie (2001) e em parceria com J.-P. Payet et Laurence Rouleau-Berger, L'école dans la ville (1994). Esses trabalhos coletivos adotam várias perspectivas metodológicas, mas a que se sobressai são as monografias de pequenas comunas e uma etnografia dos estabelecimentos escolares, confrontando à problemática da reprodução do sistema de ensino, buscando conjugar várias dimensões como a escolarização, o lugar social do estabelecimento no espaço urbano local, as formas de segregação escolar ligadas às estratégias familiares de escolarização e à concorrência entre os estabelecimentos, a experiência escolar dos alunos e a divisão do trabalho educativo (POUPEAU; FRANÇOIS, 2008, p. 205-206). O fio condutor é que as 
práticas dos agentes sociais mais afetados pelas relações de dominação contribuem para sua reprodução.

As pesquisas realizadas dentro dessa perspectiva se apoiam num método econométrico e pesquisa de campo sistemática; convidam a pensar a segregação escolar como um componente essencial de reprodução das desigualdades sociais, renovando os trabalhos no campo da sociologia da educação. Ben Ayed e Poupeau (2009, p. 10) acentuam três dimensões dentro de um conjunto de trabalhos: 1) uma análise das relações entre performance dos estabelecimentos escolares e reprodução; nesta busca-se melhorar e reforçar os dispositivos metodológicos permitindo superar a dicotomia entre etnografia e estatística, compreendendo os mecanismos em jogo e objetivando a evolução das desigualdades sociais; 2) a pesquisa concernente aos sistemas de relações entre as variáveis sociais. Aqui, acentuase o fato de que a variável étnica é particularmente pertinente nas pesquisas sobre a segregação escolar ${ }^{12}$; 3) a terceira dimensão das pesquisas sobre a segregação escolar remete à extensão do mercado escolar que inevitavelmente tem por reflexo reforçar as desigualdades no interior do espaço escolar, em particular através da acentuação das diferenciações territoriais que afetam os espaços residenciais e escolares (BEN AYED; POUPEAU, 2009, p. 100). Como vemos, os estudos sobre as desigualdades socioespaciais, da reprodução social e escolar, têm se constituído uma renovação e um renovado vigor para a sociologia da educação.

12 No Brasil, os trabalhos de Eliane Cavalleiro, Do silêncio do lar ao silêncio escolar: racismo, preconceito e discriminação na Educação Infantil (2000), através da etnografia do cotidiano escolar, têm sido importantes para a objetivação de processos segregativos a partir de aspectos culturais do processo de ensino e aprendizagem que apontam para relações sociais de dominação mais amplas. 


\section{Segregação Residencial e Segregação Escolar}

Em 2005, F. Poupeau e J.-C. François elaboraram sob a demanda do Ministério da Educação nacional um estudo sobre a disparidade territorial do sistema escolar intitulado: "Les pratiques de l'évitement scolaire en Île-de-France. De l'espace résidentiel à l'espace scolaire"13 Esse estudo coincide com o forte debate na França sobre a redução da "carte scolaire". Como dito antes, "la carte scolaire", que mantém o aluno em um estabelecimento escolar em função de seu lugar de residência, é um dispositivo administrativo colocado em prática em 1963 para garantir a igualdade de acesso à escola republicana e seu bom funcionamento, $\mathrm{e}$, mais tarde, para conservar a diversidade de origem social no interior dos estabelecimentos escolares (CARVALHO FILHO, 2013).

Em sequência, esses autores, a partir das pesquisas realizadas numa comuna do oeste de Paris, analisam a lógica social da diferenciação que regulamenta as diferenciações sociais das práticas das famílias, articulando as variáveis espaciais às variáveis sociais tradicionais, assim como às armas teóricas da sociologia da educação, da sociologia urbana e da geografia: pertencer à mesma categoria social não tem o mesmo significado nos espaços escolares diferenciados para a acessibilidade, a hierarquia dos estabelecimentos escolares e dos recursos disponíveis e mobilizáveis pelas famílias, quer dizer, as formas de capital econômico e cultural. A hipótese de um "sens du placement" (que podemos traduzir por investimento, distribuição, disposição), entendido ao mesmo tempo como direção, faculdade e significado, faz-se necessário para dar conta da capacidade das famílias de encontrar os circuitos de escolarização ajustando seus recursos, em particular, à estrutura da distribuição do capital econômico e cultural de cada família isoladamente, mas também, em relação às outras famílias nos espaços de concorrência relevante.

13 As práticas de evitamento escolar na Île-de-France. Do espaço residencial ao espaço escolar. 
François e Poupeau (2009) propõem que a análise dessas estratégias requer uma decomposição da estrutura da distribuição dos capitais, a fim de refinar os instrumentos analíticos no que se referem aos indicadores e variáveis utilizadas para apreender as diferenciações efetivas no interior das categorias sociais situadas nos circuitos de escolarização distintos.

Em artigo intitulado Le social et le spatial: quelques perspectives critiques sur l'analyse de la ségrégation scolaire ${ }^{14}$, François e Poupeau (2005) fazem uma revisão dos trabalhos realizados sobre a segregação escolar no espaço urbano, examinando criticamente o uso da noção de segregação social e espacial aplicada ao espaço escolar, anteriormente utilizada nas análises seja das desigualdades sociais de escolarização ou nas perspectivas políticas denunciando os processos de marginalização e de discriminação.

Tributários da sociologia bourdieusiana, os autores concebem o espaço urbano como "uma construção social que resulta dos procedimentos do amenagement passado ou presente" (POUPEAU; FRANÇOIS, 2008, p. 28). Explicitando a posição de Bourdieu, eles afirmam que face à visão de um espaço que agiria como constrangimento físico exógeno às práticas sociais, trata-se de explorar, de uma parte, a hipótese que as práticas espacialmente localizadas são produtos históricos e sociais e, de outra parte, a hipótese segundo a qual a dimensão espacial é uma estrutura que, conservando os laços da expressão a outras estruturas, exerce um papel específico, quer dizer, a possibilidade de ver o espaço como um princípio estruturante das práticas sociais (CARVALHO FILHO, 2013).

Essa perspectiva sociológica na abordagem da segregação espacial e escolar encontra, também, uma sociologia urbana dos espaços escolares. No entanto, se podemos nos referir a alguns trabalhos da sociologia urbana americana, disciplinas como a geografia

14 O social e o espacial: algumas perspectivas críticas sobre a análise da segregação escolar. 
econômica e a economia do espaço nos oferecem uma análise do papel do espaço, das formas de distribuição e da diferenciação dos agentes e das atividades no espaço: o espaço aqui, não é apresentado como um lugar neutro e homogêneo onde se expressaria a concorrência entre os agentes, mas como o princípio de produção de lugares distintos que favorecem a expressão da diferenciação das estratégias.

Reforçando a posição de Bourdieu, segundo a qual as maiores lutas no espaço geográfico concernem o poder de se apropriar do espaço, pode-se afirmar que o habitat, assim como a educação, se caracteriza pela sua posição no espaço, residencial e escolar, socialmente marcado. Assim, se existem condições sociais, econômicas e culturais de apropriação do espaço urbano, é necessário reconhecer que o espaço é possuído pelos agentes sociais em proporção de seus recursos econômicos e culturais. Num espaço hierarquizado, as trajetórias ascendentes e descendentes se distinguem claramente no plano espacial dos itinerários geográficos, das mudanças de residência ou de estabelecimentos escolares (POUPEAU; FRANÇOIS, 2008; CARVALHO FILHO, 2013). Nesse sentido, a distribuição geográfica dos lugares de residência e de estabelecimentos públicos expressa e reforça ao mesmo tempo esses processos sociais segregativos.

\section{Considerações Finais}

Ao longo deste artigo propôs-se um quadro analítico para uma sociologia da distribuição espacial e social dos estabelecimentos de ensino - problemática inovadora para a sociologia da educação nos últimos vinte anos - a partir de trabalhos que discutem diversas variáveis: segregação social, segregação escolar, "carte scolaire", estratégias de escolhas dos estabelecimentos de ensino. Fica evidente que pertencer à mesma categoria social não tem o mesmo significado nos espaços escolares diferenciados para a acessibilidade, a hierarquia 
(concorrência no mercado escolar) dos estabelecimentos escolares (socialmente marcados) e dos recursos disponíveis e mobilizáveis pelas famílias. Dito de outra forma, os estabelecimentos de ensino (público ou privado), que não se situam em qualquer lugar no espaço geográfico e social urbano, também não recebem qualquer um e, desse modo, não têm o mesmo projeto, as mesmas opções diferenciadas.

Um estudo sociológico em termos de segregação escolar demanda a mobilização de uma perspectiva histórica e a atenção à formação de processos sociais segregativos em escala internacional levando em conta as suas várias dimensões. Segundo OCDE ${ }^{15}$ (MERLE, 2012, p. 13-14), existem quatro tipos de "segregação acadêmica": 1) uma institucionalizada pela existência de fileiras escolares constituídas sobre a base de diferenças de níveis escolares; 2) segregação acadêmica que distingue entre si os estabelecimentos segundo o nível de competência média entre seus alunos (esta é estudada pelas pesquisas no âmbito do PISA $^{16}$; 3) segregação acadêmica resultado do modo de constituição das séries e da existência de opções e seções reservadas aos melhores alunos; 4) e a segregação que distingue os estabelecimentos em públicos e privados, resultado das escolhas feitas pelas famílias em função da concorrência pelo espaço nas escolas consideradas prestigiosas.

Uma sociologia da distribuição espacial e social dos estabelecimentos de ensino atenta aos processos sociais de segregação escolar necessita desvelar os jogos e disputas que estão por trás das razões das escolhas das experiências escolares das famílias. Embora não se proponha uma ciência social total, no campo da educação, esta perspectiva de análise suscita um olhar global sobre os fatores econômicos, culturais, mas também, as distribuições desiguais nos espaços escolares fundadas nas diferenciações de gêneros e étnicoraciais que vêm a lume com o processo de democratização do ensino

15 Organização para a Cooperação do Desenvolvimento Econômico.

16 Program for International Student Assement (PISA) 
em termos de acesso e prolongamento dos estudos. Sobre estes dois aspectos, a sociologia da educação no Brasil, ainda busca um melhor aprofundamento visando superar as lacunas no que tange a esses problemas que resulta em fracassos escolares. Digno de nota a esse respeito pode-se citar aos trabalhos nessas duas frentes. Primeiro as pesquisas de Marília Pinto de Carvalho. Em artigo sobre "Desempenho escolar, gênero e raça: desafios teóricos de uma pesquisa" (2007), a autora fornece uma contribuição sobre a relação gênero e educação, analisando os processos de desigualdades escolares produzidos nas práticas de avaliação. A questão central que Carvalho intenta responder é “quais são as ferramentas teóricas capazes de dar conta da contraditória situação de que as meninas tendem a obter melhores resultados escolares que os meninos, numa sociedade em que se verifica uma forte subordinação das mulheres em outros campos e instituições"? A análise trata de revelar significados ligados a gênero, "raça" e renda familiar e compreender processos de construção de avaliações escolares.

No que se refere à investigação educacional sobre as relações étnico-raciais e de gênero, as pesquisas etnográficas realizadas por Eliane Cavalleiro (2010) contribuem para o conhecimento de como o racismo, o preconceito e a discriminação racial e social, vigentes na sociedade brasileira, configuram-se no cotidiano escolar, muitas vezes de modo oculto.

A articulação desses três elementos (gênero, etnia, renda familiar) oferece uma contribuição sociológica pertinente à análise da segregação social e escolar no interior dos estabelecimentos de ensino. 


\section{REFERÊNCIAS}

ALMEIDA, Ana Maria F.; NOGUEIRA, Maria Alice (Org.). A escolarização das elites: um panorama internacional da pesquisa. Petrópolis: Vozes, 2003.

ALMEIDA, Ana Maria F. As escolas dos dirigentes paulistas: ensino médio, vestibular, desigualdades sociais. Belo Horizonte: Argumentum, 2009.

BEN AYED, Choukri; POUPEAU, Franck, École ségrégative, école reproductive. Actes de la Recherche en Sciences Sociales, Paris, v. 5, n. 180, p. 4-10, 2009. Disponíuvel em: $<$ https://www.cairn.info/revue-actes-de-la-recherche-en-sciences-sociales-20095-page-4.htm>. Acesso: 17 jan. 2015.

BEAUD, Stéphane. $80 \%$ au bac...et après: les enfants de la démocratisation scolaire. Paris: La Découverte, 2002.

BOURDIEU, Pierre; PASSERON, Jean-Claude. La réproduction: éléments pour une théorie du système d'enseignement. Paris: Minuit, 1999.

CARVALHO FILHO, Juarez Lopes. As contribuições de Pierre Bourdieu para a sociologia urbana. In: CONGRESSO BRASILEIRO DE SOCIOLOGIA, 16., 2013, Salvador. Anais... Salvador: Universidade Federal da Bahia, 2013.

CARVALHO, Marília Pinto. Desempenho escolar, gênero e raça: desafios teóricos de uma pesquisa. In: PAIXÃO, Lea Pinheiro; ZAGO, Nadir. Sociologia da educação: pesquisa e realidade brasileira. Petrópolis: Vozes, 2007. p. 182-202.

CAVALLEIRO, Eliane dos Santos. Do silêncio do lar ao silêncio escolar: racismo, preconceito e discriminação na educação infantil. São Paulo: Contexto, 2000.

CAVALLEIRO, Eliane dos Santos. Considerações sobre a etnografia na escola e práticas investigativas sobre as relações raciais e de gênero. In WELLER, Wivian; PFAFF, Nicole (Org.). Metodologias da pesquisa qualitativa em educação. Petrópolis: Vozes, 2010. p. 271-278.

CHARLE, Christophe. Situation spatiale et position sociale [essai de géographie sociale du champ littéraire à la fin du XIXème siècle]. Actes de la Recherche en Sciences Sociales, Paris, v. 13, n. 1, p. 45-59, fév. 1977.

DUBET, François. O que é uma escolar justa? a escola das oportunidades. Tradução de Ione Ribeiro Valle. São Paulo: Cortez, 2008.

DURU-BELLAT, Marie. La ségrégation sociale à l'école: faits et effets. Diversité: Ville, Ecole, Intégration, Paris, n. 139, p. 73-80, déc. 2004.

FIJALKOW, Yankel. La sociologie de la ville. Paris: La Découverte, 2002. 
FRANÇOIS, Jean-Christophe; POUPEAU, Franck. Le sens du placement scolaire: la dimension spatiale des inégalités sociales. Revue Française de Pédagogie, Lyon, n. 169, p. 77-97, 2009.

FRANÇOIS, Jean-Christophe; POUPEAU, Franck. Le social et le spatial: quelques perspectives critiques sur l'analyse de la ségrégation scolaire. Espace Populations Sociétés, Villeneuve d'Ascq, v. 3, p. 367-384, 2005.

GRAFMEYER, Yves. Sociologie urbaine. Paris: Nathan, 1995.

MASCLET, Olivier. Du « bastion » au « ghetto ». Le communisme municipal en butte à l'immigration. Actes de la Recherche en Sciences Sociales, Paris, n. 159, p. 10-25, 2005.

MERLE, Pierre. La démocratisation de l'enseignement. Paris: La Découverte, 2011.

MERLE, Pierre. La ségrégation scolaire. Paris : La Découverte, 2012.

NOGUEIRA, Maria Alice. A escolha do estabelecimento de ensino pelas famílias: a ação discreta da riqueza cultural. Revista Brasileira de Educação, Rio de Janeiro, n. 7, p. 42-56, jan./abr. 1998.

OBIN, Jean-Pierre; VAN ZANTEN, Agnès. La carte scolaire. Paris: PUF, 2010.

PAYET, Jean-Paul. La ségrégation scolaire: une perspective sociologique sur la violence à l'école. Revue Française de Pédagogie, Paris, n. 123, p. 21-34, avril/juin 1998.

PEUGNY, Camille. O destino vem do berço? desigualdade e reprodução social. Tradução de Vanina Carrara Sigrist. Campinas: Papirus, 2014.

POUPEAU, Franck; FRANÇOIS, Jean-Christophe. Le sens du placement: ségrégation résidentielle et ségrégation scolaire. Paris: Raison d'agir, 2008.

ROMANELLI, Geraldo; NOGUEIRA, Maria Alice; ZAGO, Nadir (Org.). Família e escola: novas perspectivas de análise. Petrópolis: Vozes, 2013.

ROMANELLI, Geraldo; NOGUEIRA, Maria Alice; ZAGO, Nadir (Org.). Família e escola: trajetórias de escolarização em camadas médias e populares. Petrópolis: Vozes, 2011.

WACQUANT, Loïc. Parias: ghetto, banlieues. Paris: État. La Découverte, 2006.

WHYTE, William Foote. Sociedade de esquina: a estrutura social de uma área urbana pobre e degradada. Tradução de Maria Lúcia de Oliveira. Rio de Janeiro: Jorge Zahar, 2005. 